\title{
Microstructure and Mechanical Property Connections for a Punched Non- Oriented Electrical Steel Lamination
}

\author{
Aroba Saleem ${ }^{1}$, Dina Goldbaum ${ }^{1}$, Nicolas Brodusch ${ }^{1}$, Raynald Gauvin ${ }^{1}$ and Richard R. Chromik ${ }^{1, *}$ \\ ${ }^{1}$ Department of Mining and Materials Engineering, McGill University, 3610 University Street, Montreal, Canada H3A 0C5.
}

\begin{abstract}
Secondary manufacturing processes used on electrical steels, such as mechanical or laser cutting, have a detrimental effect on the magnetic properties and increase the losses for electric motors. When the process is mechanical, there is both work hardening, and residual stress induced near the cut edge. The knowledge of the type of deterioration near the cut edge and the degree of deterioration is important for designing electrical machines in terms of magnetic field and loss calculations. The present paper evaluates the effect of punching on the microstructure and mechanical properties of non-oriented electrical steel. Scanning Electron Microscopy (SEM) and Electron backscattered diffraction (EBSD) analysis was performed on the cross section of the punched non-oriented electrical steel to study the evolution of microstructure and crystallographic texture near the edge whereas nanoindentation was used to determine the hardness profile. The observed mechanical properties were related to the microstructure near the edge, which was highly heterogeneous. The microstructure of the punched steel consisted of elongated grains and shear bands with ultrafine grains of size smaller than $500 \mathrm{~nm}$. The hardness was maximum in a region where shear bands were observed in the punched microstructure and the value obtained was 4.54 $\mathrm{GPa}$. This hardness increase, with respect to the average hardness of undamaged steel (3.15 GPa), was attributed to various factors such as grain refinement, work hardening and residual stress. Finally, pop-in analysis was done to study the extent of work hardening due to punching and its effect on hardness. The zero pop-in region was extended to a distance of $200 \mu \mathrm{m}$ from the edge in the fracture section whereas it was $50 \mu \mathrm{m}$ in roll over section.
\end{abstract}

Keywords: Punching, non-oriented electrical steel, microstructure, shear bands.

*Richard Chromik, Email: richard.chromik@mcgill.ca, Phone: 514-398-5686 (Corresponding author), Aroba Saleem,Email: aroba.saleem@mail.mcgill.ca, Dina Goldbaum, Email: dina.goldbaum@mail.mcgill.ca, Nicolas Brodusch, Email: nicolas.brodusch@mcgill.ca, Raynald Gauvin, Email: raynald.gauvin@ mcgill.ca 


\section{Introduction}

Manufacturing processes used for electrical steels, such as laser cutting, guillotining and punching, change the material's microstructure, create residual stresses, and affects the magnetic performance. Mechanical punching is a popular, low cost and easy to use process to fabricate machine cores from electrical steel laminations [1], [2]. This method introduces plastic deformation near the edge and therefore, creates a damaged region with increased hardness due to residual stress and work hardening. These effects along with other microstructural changes will cause deterioration in magnetic properties such as increase in losses and drop in flux for a given field strength [3]-[5].

Non-oriented electrical steel (NOES) is a magnetically soft ferromagnetic material, which is manufactured in the form of laminations [6]. NOES is a class of steel with $3 \% \mathrm{Si}$ and is characterized by $\{100\}\langle\mathrm{uvw}\rangle$ as a favourable texture component, where $<100\rangle$ direction, which is easy to magnetize, is randomly oriented along the plane of the sheet [7]. Owing to its isotropic nature in terms of magnetic properties, non-oriented electrical steel (NOES) is widely used as a core material for magnetic flux transfer in motors and as such is one of the most important magnetic material in power and machine industry [6].The effect of punching on the magnetic properties has been investigated in the literature by direct magnetic property measurement [1], [8], [9] or study of microstructural modification near the punched edge [4], [10]. A recent work by Xiong et al. [10] studied the changes in microstructure of the mechanically cut non-oriented electrical steel (NOES) lamination and tried to relate the microstructural changes to the magnetic deterioration. The microstructure of the top surface and bottom surface was separately analysed by electron back scattered diffraction (EBSD) and the increase in misorientation angle distribution near the edge was reported. Similar results were reported by Harstick et al. [4] where EBSD was used to observe local change of properties. The misorientation angle distribution gives an idea about the dislocation density where high misorientation angle represents more dislocations. The dislocations act as pinning sites for the movement of magnetic domains resulting in the increase in losses [4]. In addition to the increase in dislocation density near the edge, punching causes severe plastic deformation, which can change the grain morphology of the sample. 
The effect of the punching process on the material can be understood as a series of consecutive events. First, the punch comes in contact with the metal sheet causing it to roll over. This leads to an increase of the load until it reaches fracture shear stress of the metal. At this stage of punching, the load increases until a crack is initiated leading to ductile fracture and the formation of burr [10], [11]. Thus, the cross section of the punched edge can be divided into four sections: roll over, the shear zone, the ductile fracture and the burr.

In addition to the microstructural modifications near the edge, punching induced residual stresses will also lead to the deterioration of magnetic properties. It is difficult to measure residual stresses induced by punching experimentally, however, some researchers in the past used microhardness to measure internal stress due to mechanical cutting [1]. The main issue with this method is that hardness is affected both by work hardening as well as residual stress and, therefore, the hardness change cannot be attributed to residual stress only. Further, some researchers tried to measure residual stresses by x-ray diffraction [12] but the measurement was not limited to the edge of the punched lamination. Therefore, finite element analysis has been done recently by Weiss et al. [13], Fujisaki et al. [14] and Kashiwara et al. [15] to analyze the residual stress distribution in the punched lamination.

The present work focusses on the microstructural modifications near the edge due to punching and its relation to mechanical properties. An idea of hardness change only due to residual stresses is given in this paper by relating nanoindentation measurements with microstructure. Hardness and pop-in displacement are used along with microstructural characterization to determine not just the extent of damage in the steel, but also the nature of the damage in the different regions of the steel. This information on the precise nature of the material modifications due to punching are useful for understanding better the effects of these phenomenon on magnetic properties. Understanding the mechanical property and microstructure changes due to punching can help the materials engineers and motor designers to better account for the extent of damage and the effect on the magnetic properties. 


\section{Experimental}

\section{Material}

The material studied was a punched NOES lamination of grade $35 \mathrm{WW} 250$ which was provided by the TM4 Company. It was punched into a motor lamination design (150 mm outer diameter) by standard industrial process. In a standard punching process, the punch press is used to force a tool, called a punch, through the lamination to create a hole. A die is located on the other side of the lamination to support it during punching as shown in Fig. 1. The punch and die are close to the same dimensions causing shearing at the edge where they meet. The clearance between the punch and the die generally range between $2 \%$ and $10 \%$ of the sheet thickness [11].

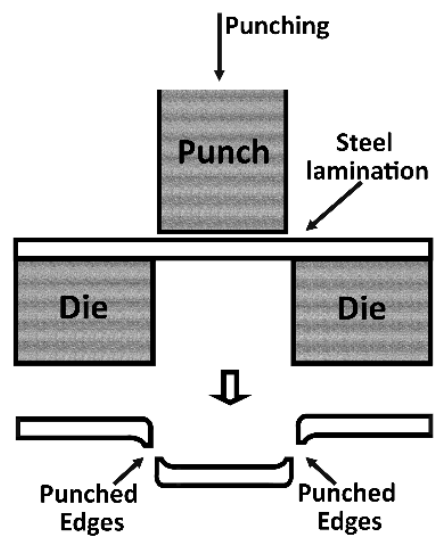

Fig. 1 Schematic illustration of designing the sheet metal by punching, indicating the formation of burr near the punched edges.

\section{Microstructural Characterization}

For microstructure investigations of the punched edge, Hitachi SU8000 and SU3500 electron microscopes with Oxford Instrument Nordlys II EBSD camera were used. The EBSD system on the SU3500 and SU8000 SEMs were controlled by the Aztek and Channel 5 software, respectively. Band contrast (BC) and inverse pole figures (IFP) maps were generated using Tango, which is part of the Channel 5 software suite. EBSD analysis and nanoindentation require a flat and highly polished surface. The steel cross sections were cold mounted in an epoxy resin, ground to 1200 grit $\mathrm{SiC}$ paper followed by polishing using $3 \mu \mathrm{m}$ and $1 \mu \mathrm{m}$ oil-based diamond suspension. 
Finally, the vibratory polishing was performed for $\sim 20$ hours using $0.05 \mu \mathrm{m}$ colloidal silica suspension [16]. Lower magnification ( 200 X) EBSD and band contrast maps were obtained with the SU3500 in VP-SEM mode (Vapour pressure mode) and at an accelerating voltage of $20 \mathrm{kV}$. This mode was selected to avoid the charging effect in the image due to non-conductive resin. For high resolution EBSD maps, the SU8000 was used to reduce the lateral spatial resolution of the EBSD analysis owing the nanometer scale probe size of the microscope. In some cases, the surface condition of the sample was improved by ion milling before obtaining high resolution maps using an Hitachi IM3000 $\mathrm{Ar}^{+}$flat milling system. The accelerating voltage, incident angle from the specimen surface and milling time were $5 \mathrm{kV}, 7^{\circ}$ and 30 minutes, respectively. To avoid charging due to non-conductive resin mount and for better beam stability, the mounted specimen was coated with chromium with a coating thickness of $2 \mathrm{~nm}$. Areas near the punched edge were also analysed using the electron channeling contrast (ECC) obtained via back scattered electron (BSE) imaging using the SU8000 at an accelerating voltage of $5 \mathrm{kV}$. The BSE detector was a solid-state photodiode detector located below the SEM pole-piece. Grain size was calculated by mean lineal intercept method from SEM micrographs [17].

\section{Nanoindentation}

Nanoindentation measurements were carried out on the cross section of the tooth of motor lamination (Fig. 2) at room temperature using Hysitron Ubi Indenter. The tooth of the motor was $5 \mathrm{~mm}$ wide with a thickness of $0.35 \mathrm{~mm}$. The tests were conducted with a calibrated diamond Berkovich indenter tip. The hardness and reduced modulus of steel specimens were determined from nanoindentation tests using a standard Oliver and Pharr analysis [18]. The reduced modulus, $E_{r}$, of the sample was calculated from stiffness measurement obtained from the unloading slope and area function of the diamond indenter and is defined as follows (Eq. 1):

$$
\frac{1}{E_{r}}=\left.\frac{1-v^{2}}{E}\right|_{\text {sample }}+\left.\frac{1-v^{2}}{E}\right|_{\text {Indenter }}
$$

where $v$ is the Poisson's ratio and $E$ is the Young's modulus. The values of Poisson's ratio and Young's modulus for diamond indenter are 0.07 and $1140 \mathrm{GPa}[18]$. 
Loading and unloading each lasted $5 \mathrm{~s}$ with the maximum force of $5 \mathrm{mN}$ and the hold period was 2 s. Indentation was performed in rows starting from the punched edge of the sample towards the centre with the spacing of $\sim 20 \mu \mathrm{m}$ between the indents as shown in Fig. 2. The load displacement curve for one indent is shown in Fig. 3 where the indent was performed away from the damaged region. There is a discontinuity in the loading curve at lower loads due to the generation of dislocations that marks the transition from elastic to plastic region. This is called pop-in effect [19]. The ability to observe pop-in may be reduced by conventional mechanical polishing [20], due to near-surface damage. The damage can be reduced by taking appropriate care in polishing and the inclusion of a final step of vibratory polishing. After sample preparation, an indentation test in the middle of a large grain exhibits pop-in as shown in Fig. 3. If significant damage from polishing remained, observation of pop-in of this type would not be possible. Thus, the polishing procedure was optimized for minimal effect of residual polishing damage. Similarly, indentation size effect (ISE) of the variety caused by polishing damage [20] was also avoided.

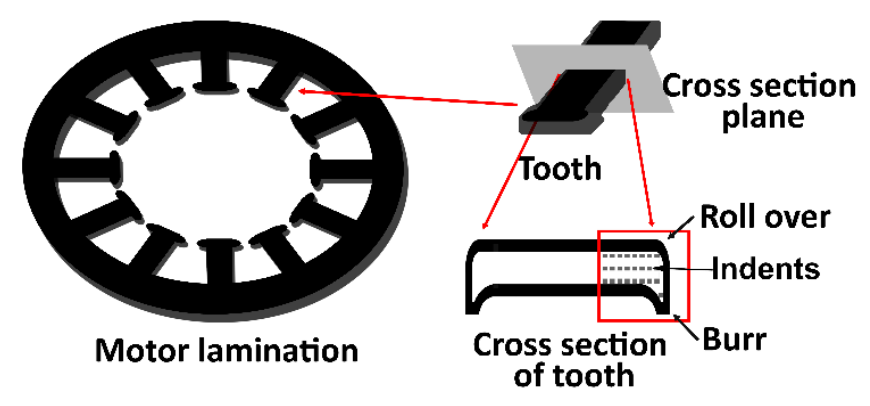

Fig. 2 Motor lamination with segmented sections, called as teeth of the lamination, prepared by punching. A single tooth and its cross section is shown to locate the area of interest in the present study. The region within the red box describe the position where nanoindentation and SEM measurements were performed. 


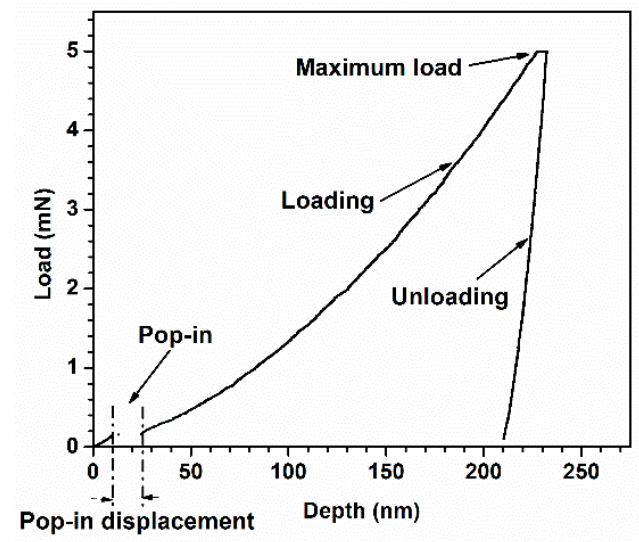

Fig. 3 Load versus displacement curve for the given non-oriented electrical steel, indicating the occurrence of pop-in event. The indent was performed in the region away from the punched edge.

\section{Results}

\section{a) Microstructure and Texture}

The SEM micrographs (BSE image) of the cross section of 35WW250 punched sample far away from and at the edge are shown in Fig. 4. From Fig. 4 (a), the region away from the cut edge is observed where undeformed grains are visible due to electron channelling contrast caused by the differences in crystallographic orientation. From images like this in surface view and the number of others, the average grain size was measured to be $120 \pm 21 \mu \mathrm{m}$. Fig. 4 (b) shows the other contrast effects due to severe plastic deformation near the punched edge. Due to plastic deformation, there is generation of dislocations and other crystal defects along with the residual stress that results in a complex microstructure as seen in ECC images. There are point-to-point changes in orientation due to lattice curvature within the deformed grain that results in bend contours [21]. These bend contours are observed in region 3 of the microstructure in Fig. 4 (b). The deformation structure appears to be heterogeneous with different microstructural features at different points, such as region 1 represents finer elongated grains and region 2 represents deformed area where grains are not visible. In addition, there is a region in the microstructure, region 4 , where an undeformed grain is present. 

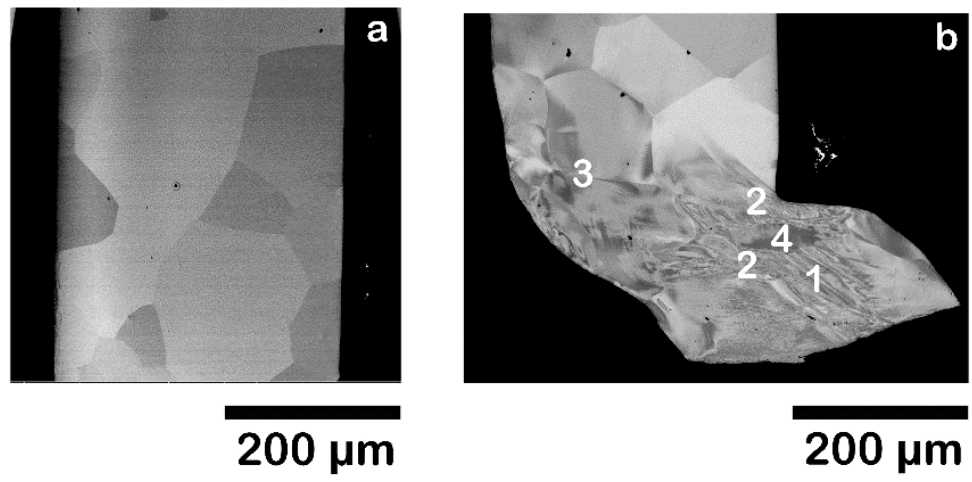

Punching

Fig. 4 Electron channeling contrast (ECC) micrographs of the cross section of 35WW250 steel. The micrograph on the left (a) is the cross section of the steel sheet away from the edge which shows the undeformed grains. The image on the right (b) is the cross section of punched edge which indicates the formation of burr and other microstructural inhomogenities. Regions in the figure (b) are highlighted to represent different microstructural features.

Band contrast and Inverse Pole figure maps (Fig. 5) of the punched edge were constructed from EBSD data. Deformation bands (shear bands), formed due to severe plastic deformation at the edge, are clearly recognised as linear features with poor pattern quality in region 2 in Fig. 5, resulting in dark areas in band contrast map. The EBSD pattern quality generally becomes worse with increasing crystal lattice distortions due to a high dislocation density [22]. The poor EBSD pattern quality indicates that the stored energy of the grain is high, whereas high EBSD pattern quality represents low stored energy [22]. The deformation structure observed at the punched edge is highly heterogeneous as seen from the EBSD data (Fig. 5), which is in agreement with the ECC micrographs (Fig. 4 (b)). This is mostly due to the fact that the deformation structure depends on the orientation of the deformed grains [23]. In addition, there are regions (region 2) in Fig. 5 which corresponds to a high density of shear bands. These shear bands consist of high angle grain boundaries deforming with different slip systems rotated towards higher misorientations [24].

Similar microstructural observations were made on another tooth of the punched 35WW250 steel lamination and the band contrast images are shown in Fig. 6. An apparent higher density of shear bands was observed at the point where burr started to form (region 2). Elongated grains are inclined to the punching axis forming a splintered or fish bone microstructure (region 1). In addition, there is no undeformed grain within the burr section (region 4), as was in the case of previous tooth region (Fig. 4 and Fig. 5). So, in general there are different microstructural 
features that are observed in the punched steel, such as, elongated grains (region 1) and shear bands (region 2).

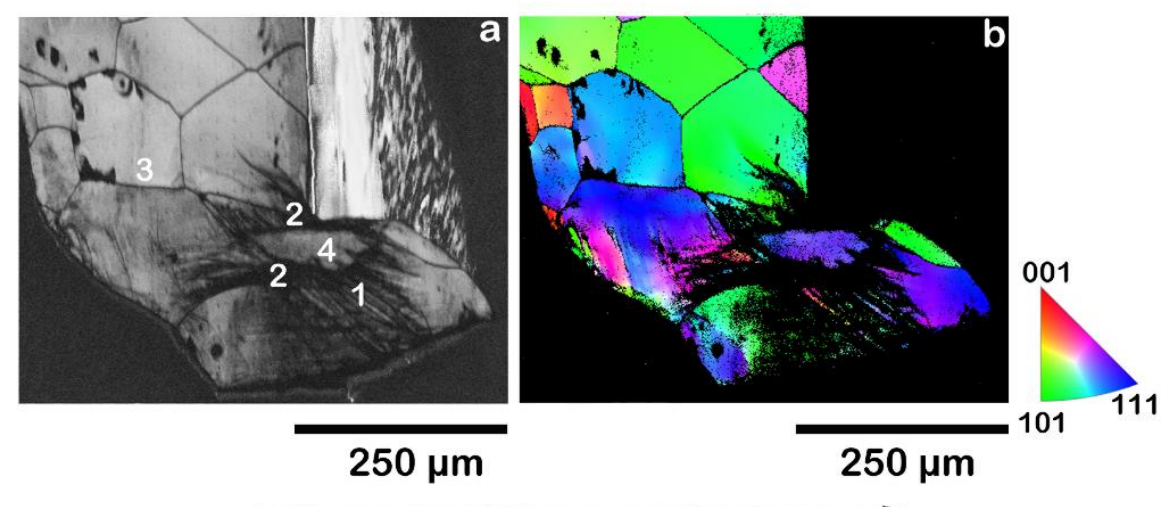

Punching

Fig. 5 Band contrast (a) and Inverse pole figure (b) EBSD maps of the cross section of punched 35WW250 steel. Four regions (regions 1-4) are highlighted in the figure, which matches with those in Fig. 4.
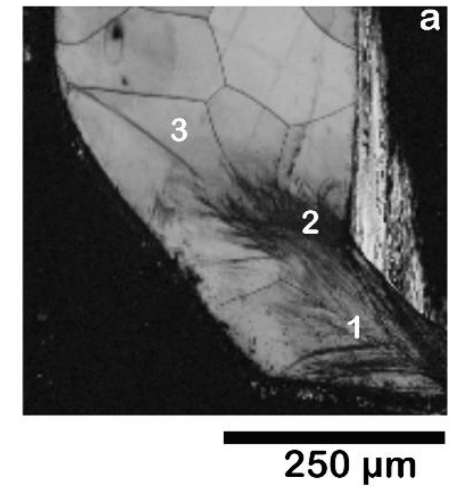

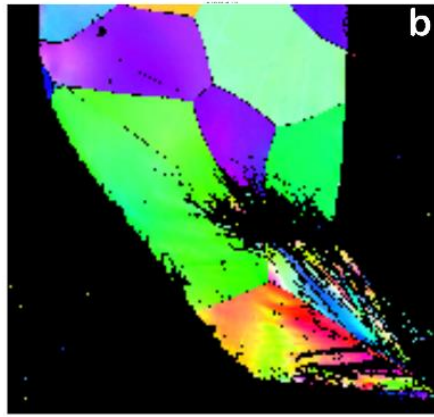

$250 \mu \mathrm{m}$

\section{b}

001

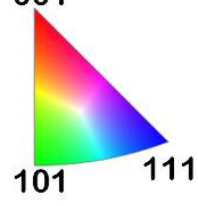

Punching

Fig. 6 Band contrast (a) and inverse pole figure (b) EBSD maps of cross section of punched 35WW250 steel from another tooth of the steel lamination (see Fig. 2). The highlighted regions are similar to those marked in Fig. 4 and Fig. 5.

The band contrast map along with inverse pole figure for the region with elongated grains (region 1 from Fig. 5) at higher magnification is shown in Fig. 7. These flattened grains are formed in $\{110\}$ orientations, which is one of the slip planes for bcc metal and are elongated in a direction 
inclined to the punching direction. This is in good agreement with the fact that these ribbon grains develop from the regions of stable crystal orientations [24]. Also, stored energy for $\{110\}$ is higher compared to $\{111\}$ and $\{100\}$ which means slip starts on $\{110\}$ orientation [23]. From Fig. 7 , shear bands have started forming perpendicular to the ribbon grains, which implies that the ribbon grains can further break up into submicron grains at higher strains.

The development of shear bands is a mechanism of accommodating large strains. Different sets of shear bands are observed in the sample as shown in Fig. 4 and Fig. 5 (region 2). Individual shear bands were successfully imaged by SEM and consisted of submicron sized grains (Fig. 8). This implies that the new fine grains are not evolved homogenously throughout the deformation structure by severe plastic deformation but mainly inside the shear bands.

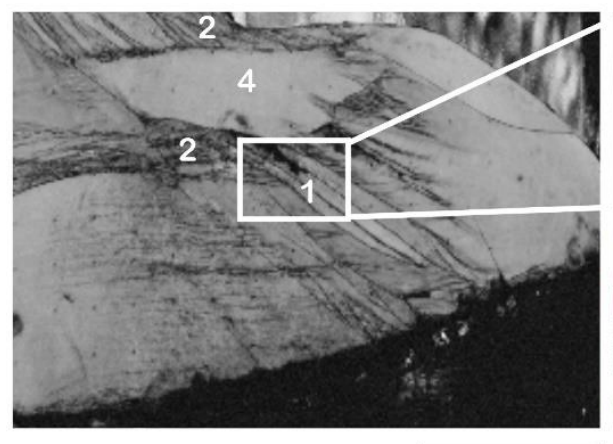

$100 \mu \mathrm{m}$
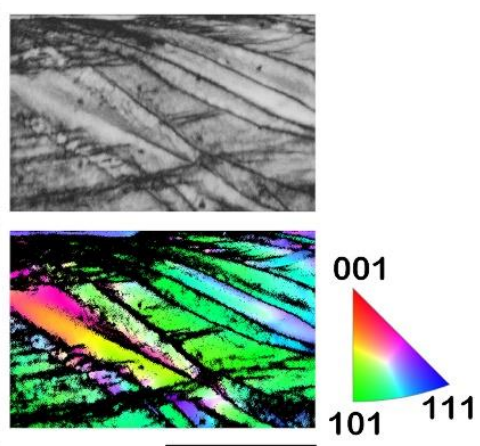

$50 \mu \mathrm{m}$

Punching

Fig. 7 Band contrast and inverse pole figure EBSD map of the burr section (cross section) of punched $35 \mathrm{WW} 250$ steel (see full scan in Fig. 5). This image also highlights regions 1, 2 and 4 from Fig. 5. 

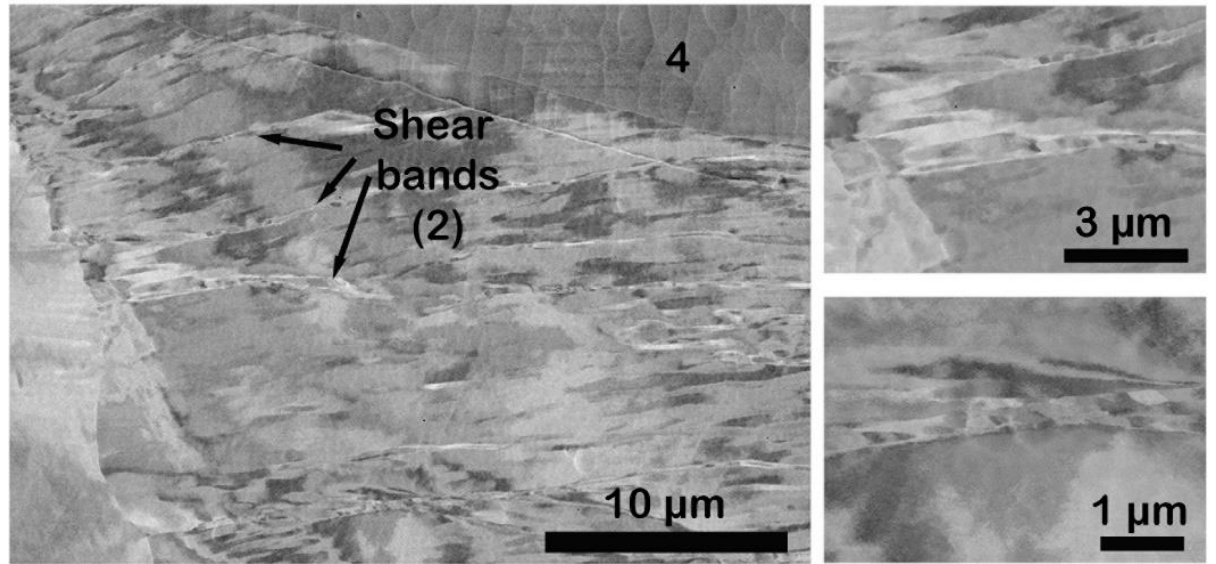

Fig. 8 ECC images of shear bands observed in the damaged region in 35WW250 steel. It gives a magnified view of region 2 from Fig. 4.

The band contrast and inverse pole figure maps of the shear bands (those from region 2 of Fig. 5) are shown in Fig. 9. Ultrafine grains with grain size smaller than $500 \mathrm{~nm}$ are found within the shear bands. The shear bands are mostly found in the region where burr starts to form (region 2 in Fig. 5), which is known to be a region that experienced high strain.

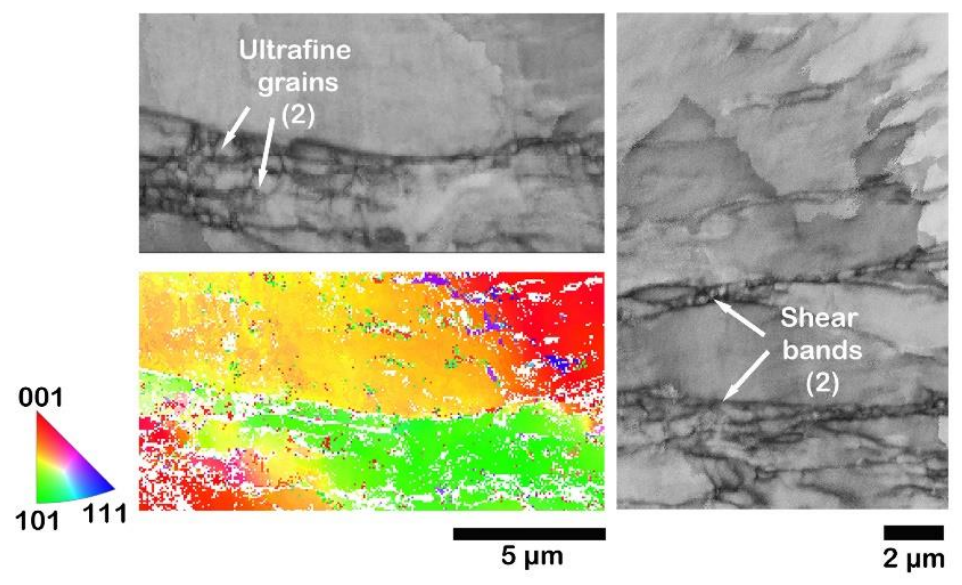

Fig. 9 Band contrast and Inverse pole figure EBSD map of shear bands observed in the damaged region in 35WW250 steel (region 2 from Fig. 5). 
From the ECC images in Fig. 4 and band contrast maps in Fig. 9, the damaged regions were highly heterogeneous with different microstructural features at different points. The microstructural features formed during the severe plastic deformation depends on the level of strain in the material [24]. This implies that the regions in the punched sample underwent different levels of strain that results in ultrafine grain development within shear bands in one section and ribbon grains in another. Some grains in the damaged zone are not changed but some contrast was observed within the grains by electron channelling (region 3 in Fig. 4).

\section{b) Nanoindentation}

Load-displacement curves, measured by nanoindentation, from different regions of the cross section (Fig. 4 and Fig. 5) of the given steel sample, are shown in Fig. 10. At a constant load of $5 \mathrm{mN}$, the indentation depth is maximum for undamaged area (Fig. 4 (a)) and decreases in the damaged region (Fig. 4 (b)), which means the hardness increases in the damaged area. Also, inside the damaged region the hardness varies from one region to another depending on the distance from the cutting edge, which may be linked to the microstructure. The curve for undamaged area shows an obvious pop-in behaviour whereas no pop-in is observed in damaged regions.

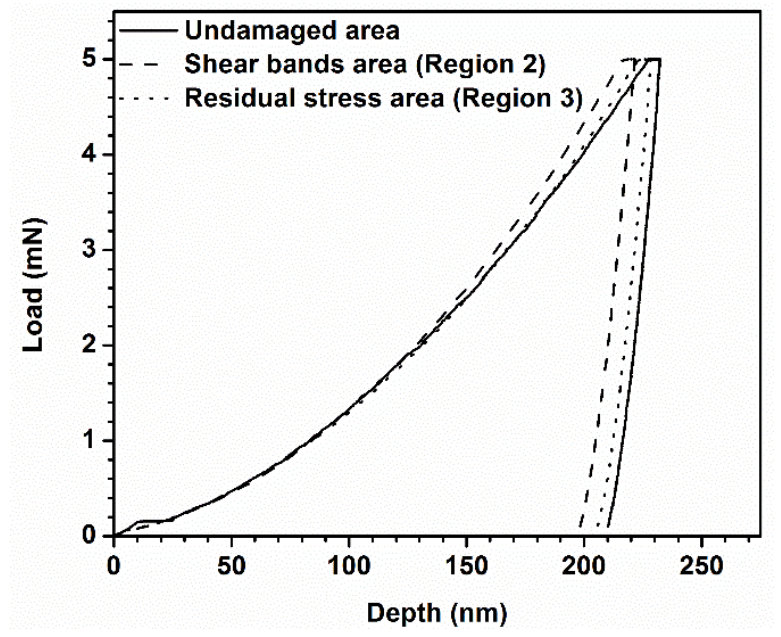

Fig. 10 Representative load displacement curves from three different regions of cross section of punched 35WW250 steel. The undamaged area corresponds to the area in the image at the left in Fig. 4. Region 2 and region 3 are the regions highlighted in the right-hand side image (b) in Fig. 4. 


\section{c) Hardness profiles}

The hardness profiles of the cross section of the sample (Fig. 4) were obtained from nanoindentation near the punched edge. The scanning electron image of the rows of indents near the punched edge is shown in Fig. 11.
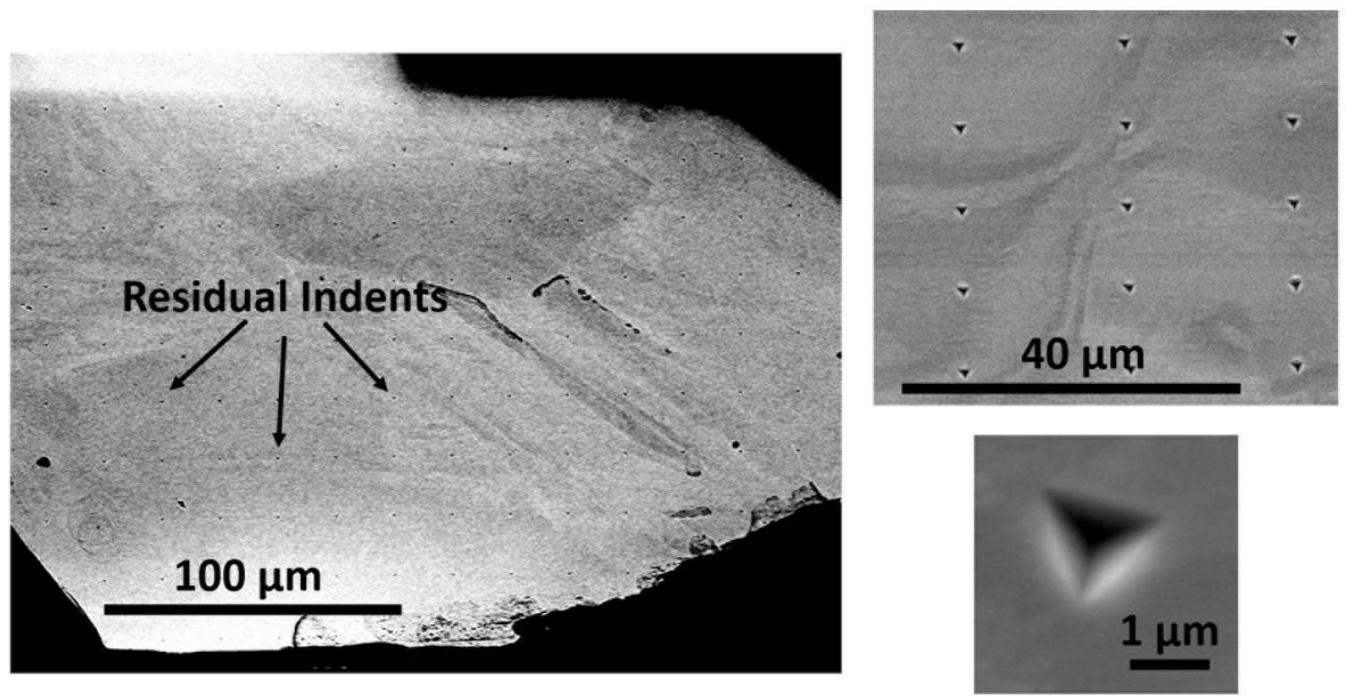

Fig. 11: Scanning electron image of the cross section of punched $35 \mathrm{WW} 250$ steel indicating the residual indents after nanoindentation.

Hardness profiles were different for different sections: roll over, sheared, fracture and burr section. This change in hardness was attributed to the different microstructural features (highlighted regions in Fig. 4 and Fig. 5) associated with each section due to different strain levels. Therefore, the total hardness in the damaged region can be written as (Eq. 2) [25]:

$$
H=H_{0}+H_{G R}+H_{R S}+H_{W H}
$$

Where $H_{0}$ is the average hardness of the undamaged region (Fig. $4 \mathrm{a}$ ), $H_{G R}$ is the hardness change due to grain refinement (region 1 and 2 in Fig. $4 \mathrm{~b}$ ), $H_{R S}$ is the hardness change due to residual stress (region 3 in Fig. $4 \mathrm{~b}$ ) and $H_{W H}$ is the hardness change due to work hardening. Work hardening is the strengthening of the material due to increase in dislocation density caused by plastic deformation. Region 2 in Fig. 5 represents the high dislocation density regions because of poor quality EBSD in those regions. Fig. 12 shows an ECC image of the sample indicating different 
sections where nanoindentation measurements were performed. The figure also gives an idea of the type of residual stress induced based on previous literature [15], [26].

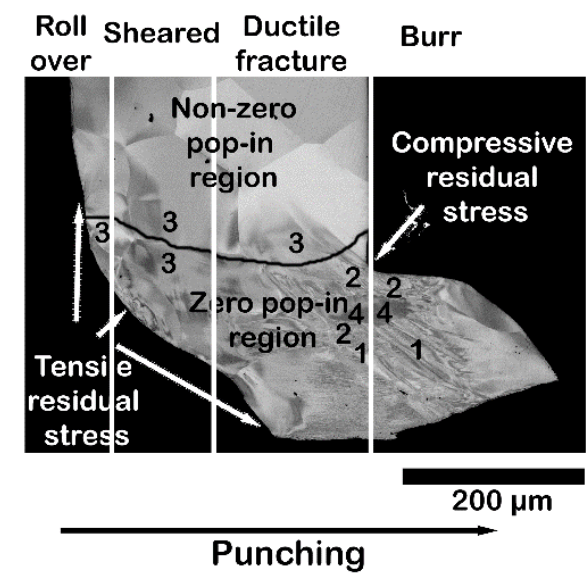

Fig. 12 ECC image of the cross section of punched 35WW250 steel (see Fig. 4) indicating different sections namely: roll over, sheared, ductile fracture and burr.

\section{i. Roll over}

The hardness as a function of distance from edge for roll over section is shown in Fig. 13. The hardness near the punched edge is increased to $3.5 \mathrm{GPa}$ compared to the bulk hardness of the steel which is $3.15 \mathrm{GPa}$. The microstructure of punched edge is shown in Fig. 4 and Fig. 5 which clearly indicates that there is no change in the grain size in roll over section but the residual stress is induced (region 3 in Fig. 4). The strain in this section was not high enough to start the formation of shear bands or ultrafine grains. Therefore, hardness change for this section can be attributed to residual stress and work hardening.

\section{ii. Sheared}

The hardness profile of sheared section is shown in Fig. 14. The hardness increase in this section is higher than that of roll over and maximum hardness is increased to $\sim 4 \mathrm{GPa}$. The microstructure of this section is comprised of grains with no change in grain size and residual stress induced which can be seen from Fig. 4b (region 3). 


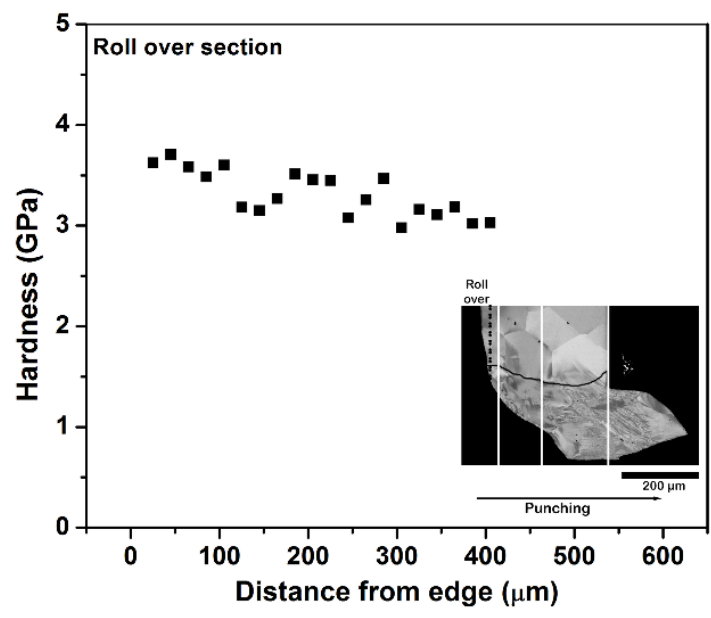

Fig. 13 Hardness vs distance from the edge in roll over section is shown. This section mainly consists of region 3 (residual stress), which is clear from Fig. 4 and Fig. 5.

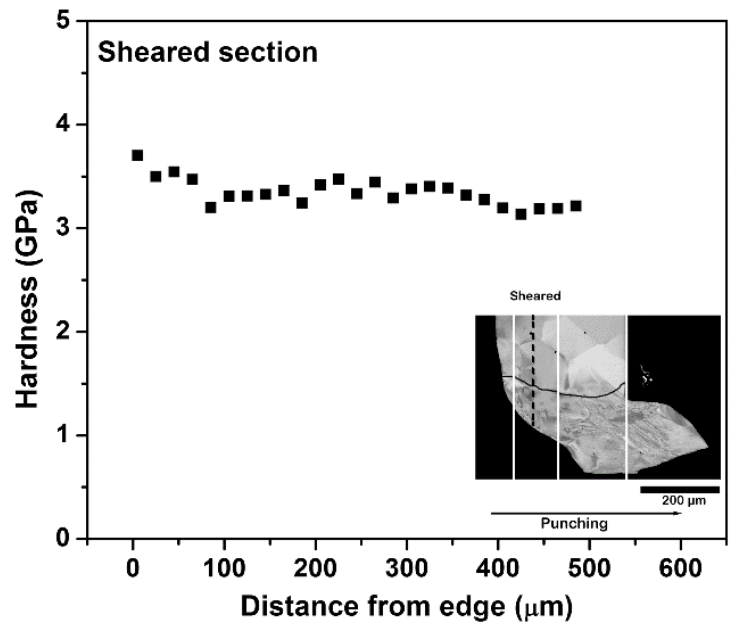

Fig. 14 Hardness vs distance from the edge in sheared section is shown. This section mainly consists of region 3 (residual stress), which is clear from Fig. 4 and Fig. 5.

iii. Ductile fracture

Ductile fracture section starts when the applied stress is enough to initiate a crack for the rapid breakthrough of the sheet which involves a ductile fracture. The relation between hardness and distance from the edge is shown in Fig. 15. The hardness shows an increasing trend initially, 
reaches a maximum and then decreases to the average bulk hardness. The microstructure of this section (Fig. 4 and Fig. 5) consists of ultrafine grains within the shear bands and also residual stress induced grains with no change in grain size. Tensile residual stress is present near the edge which results in lower hardness [13]-[15], [26] and then, hardness increase can be attributed to higher density of dislocations in the shear band area (region 2 below region 4 in Fig. 4). The peak hardness is also due to the combined effect of compressive residual stress and higher dislocation density near the point where burr started to form (shear band area in region 2 above region 4 in Fig. 4). Fujisaki et al [14] confirmed the presence of compressive residual stress at this point by finite element simulations. Higher density of dislocations is due to work hardening and hence, the hardness change can be attributed to work hardening, residual stress and grain refinement.

\section{iv. Burr}

A burr was observed in the punched sample, which is formed by plastic deformation. The hardness profile in the burr section shows that hardness throughout this section is higher than the bulk hardness of the sample (Fig. 16). The microstructure is comprised of shear bands and elongated grains, formed as a result of severe plastic deformation.

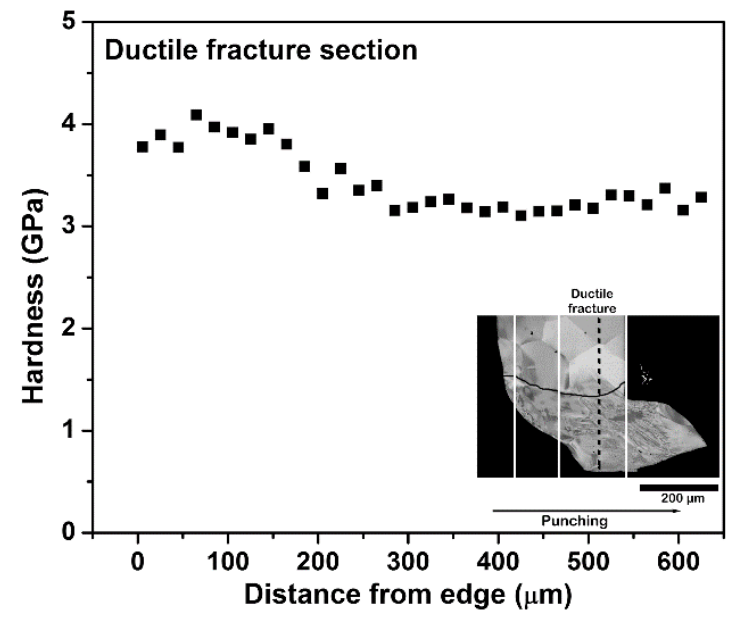

Fig. 15 Hardness vs distance from the edge in fracture section is shown. This section mainly consists of region 2 (shear bands) which is clear from Fig. 4 and Fig. 5. The microstructure in this section also consists of region 1, 3 and 


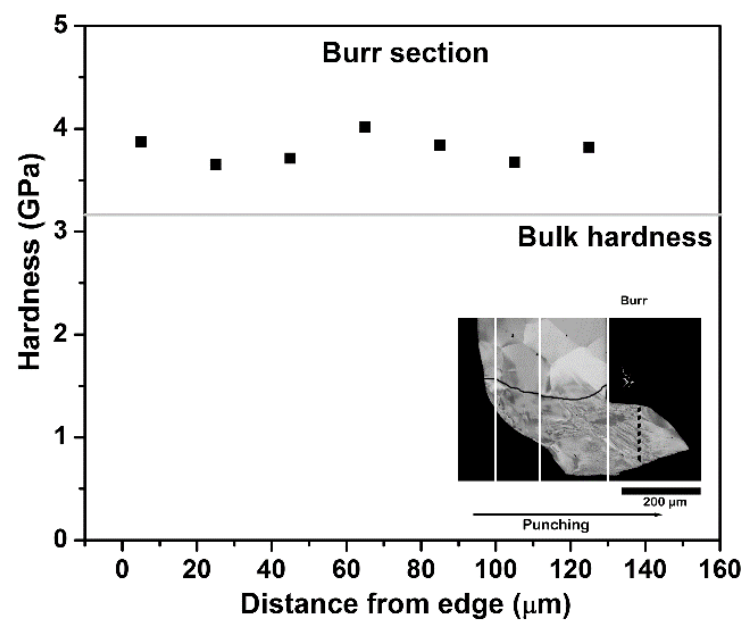

Fig. 16 Hardness vs distance from the edge in burr section is shown. This section mainly consists of region 1 (elongated grains) which is clear from Fig. 4 and Fig. 5. The microstructure in this section also consists of region 2 , 3 and 4.

\section{d) Pop-in analysis}

The pop-in analysis is used to separate the work hardened region and ultrafine grained region from residual stress region. Zero pop-in displacement means that the dislocation density is high enough or the grain size is small enough for smooth transition from elastic to plastic region. Thus, the hardness increase in zero pop-in regions must include work hardening effect, ultrafine grains or both. The pop-in displacement versus distance plots for all the four sections, roll over, sheared, ductile and burr section, is given in Fig. 17. The distance of zero pop-in is maximum for ductile fracture section compared to other sections. There is an increasing trend of pop-in displacement versus distance beyond zero pop-in region for all the sections. Also, zero pop-in displacement is observed for some indents away from the damaged area. This is due to the fact that the indent was on grain boundary, precipitates or other material defects which has higher dislocation densities than the grain interiors [27].

The difference in the pop-in behaviour in damaged and undamaged areas from all the four sections is because of the difference in density of dislocations. The density of dislocations in the damaged region is high, thus the probability of mobile dislocations underneath the indenter is significantly high. Therefore, plasticity can be initiated by the activation of existing mobile 
dislocations resulting in very low (or zero) pop-in displacement. The region with low dislocation density have lesser mobile dislocations and hence, nucleation of dislocation occurs during indentation resulting in a significant pop-in displacement. The movement of pre-existing dislocations require lower loads than nucleation of dislocations [28]. Also, higher pop-in load corresponds to higher pop-in displacement and vice versa as shown in Fig. 18. Hence, the increasing trend of pop-in displacement with distance away from the punched edge can be explained by dislocation theory [29].

Hence, the hardness profiles and pop-in behaviour vary in these four sections as discussed above based on the microstructure. In addition to the hardness and pop-in measurements, reduced modulus, $E_{r}$, was also derived from nanoindentation tests [18]. The reduced modulus values at different points as a function of distance from the edge is shown in Fig. 19. The reduced modulus seems to have a constant value throughout and the average value is around $218 \mathrm{GPa}$.

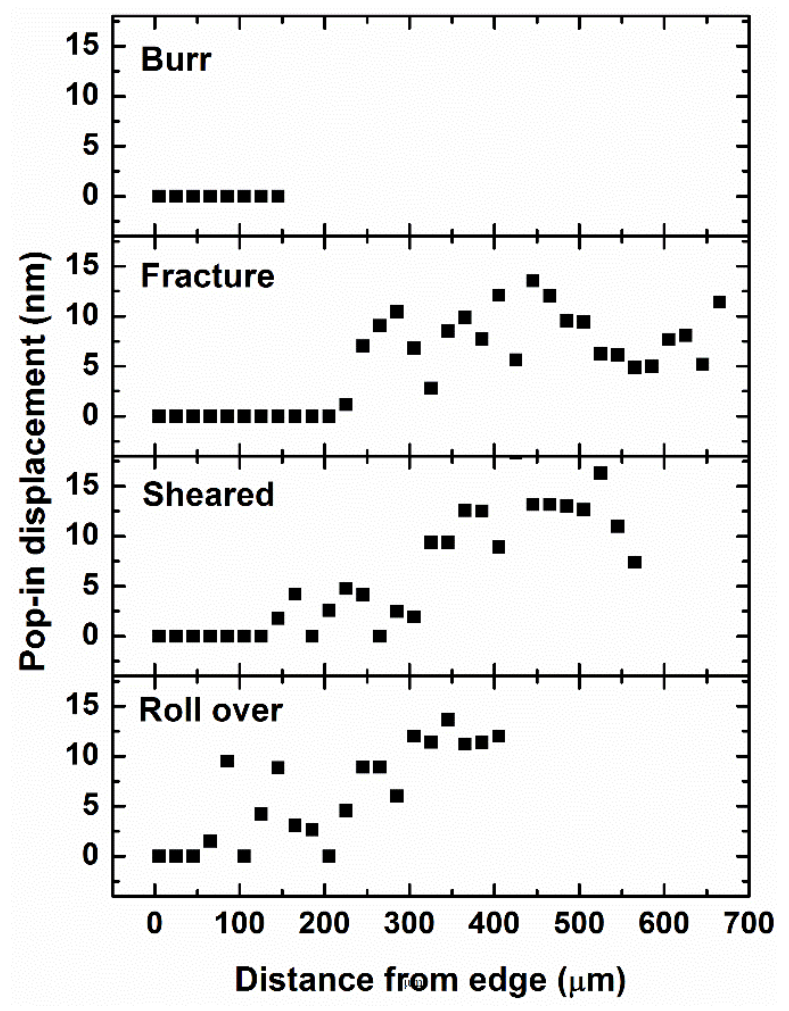

Fig. 17 Pop-in displacement vs distance for all the sections in cross section of punched 35WW250 lamination from Fig. 12. 


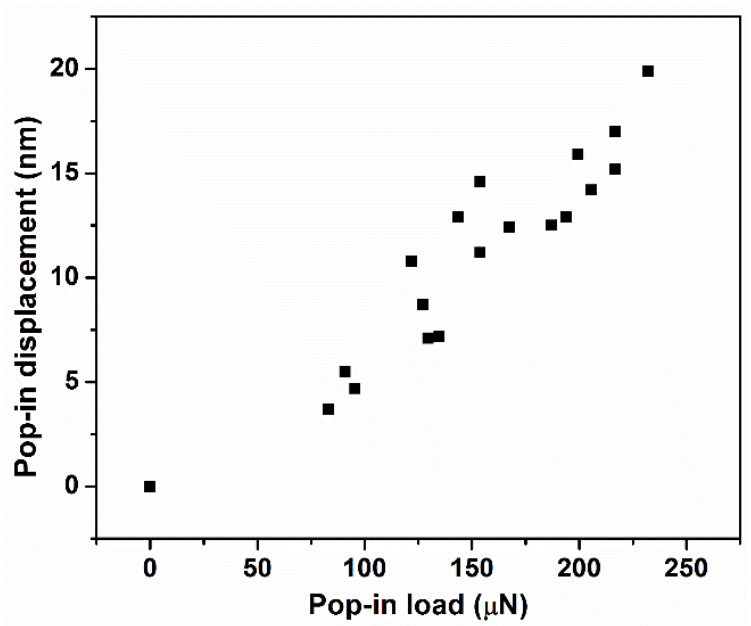

Fig. 18 Pop-in displacement vs pop-in load of the cross section of punched 35WW250 steel. The figure indicates that higher loads are required for higher pop-in displacement. The figure corresponds to the pop-in displacement curves from Fig. 17 focussing on the region beyond the zero pop-in area.

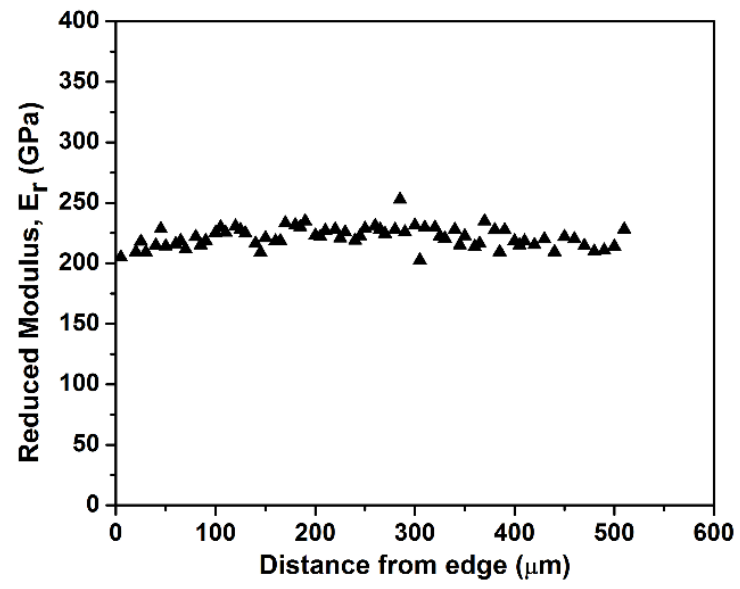

Fig. 19 Reduced modulus of the given steel lamination vs distance from the edge for few rows of indents.

\section{Discussion}

Electrical steel is a large-grained ferrite with a relatively low density of dislocations [30]. Punching induces work hardening, residual stress and microstructural changes, such as grain refinement and formation of shear bands. The nanoindentation response of such dramatically different microstructures is very different. During a nanoindentation test on a single grain with relatively low dislocation density, the first stages of plasticity often initiate suddenly and are identified on the loading curve by a so-called "pop-in" [19], [29]. This phenomenon is associated 
with dislocation activity like dislocation nucleation and dislocation pile ups. When an indentation tip approaches a surface, a load on the tip will cause the dislocations to multiply and expand, which results in the penetration of the tip in the sample [31]. This implies that the material is elastically and plastically deformed around and underneath the tip, which is represented by the region before pop-in and after pop-in in the load-displacement curves, respectively. As the density of preexisting dislocations increases, the load, frequency and width of the pop-in decrease [19], [29]. The pop-in phenomenon is also influenced by other factors, such as crystal orientation, grain boundary and inclusions. A zero pop-in displacement is observed at the grain boundary, which is due to the participation of dislocations within the grain boundary in the continuous motion of the indenter tip. Since, the formation of ultrafine grains results in an increase in the grain boundary area, the pop-in displacement is zero in these regions (region 2 from Fig. 4 and Fig. 5).

The microstructural observations near the punched edge, as shown in Fig. 4 and Fig. 5, suggests that the level of strain varies from one point to another within the damaged region, which results in the formation of different microstructural features during punching [24]. During the initial stages of punching (which is mainly represented by roll over and sheared sections), some significant orientation gradients were found within the distorted original grains, indicated by bend contours in Fig. 4 (region 3). As the punching process continues, the strain level inside the material is increased, which reaches its maximum at fracture. This results in the formation of ribbon grains (elongated grains) that develop from stable crystal orientations and continue to decrease in width with strain [24]. The regions with unstable crystal orientations with high strain levels gives rise to bands of much finer grains, which can be due to the high angle grain boundary density in those areas. The development of shear bands subdivides the cellular structure and a deformation substructure with a number of mutually crossed bands evolved at higher strains, which was observed in fracture and burr section of the sample. The points of intersection of shear bands can be considered as a preferential site for the development of highly misoriented submicrocrystalline structure [32]. The difference between the stable elongated grains and the ultrafine grains within the shear bands reflects the extreme ends of the rate of grain subdivision. Also, occasional transverse boundaries were observed within the ribbon grains (Fig. 7) that have not yet formed the continuous boundary breaking down the grains. This occurs due to the heterogeneity in the plastic flow. 
Punching also affects hardness profiles near the edge. The hardness change near the edge in roll over section (Fig. 13) is attributed to the plastic strain and tensile residual stress with no significant microstructural change (Fig. 4 and Fig. 5). It was confirmed by Kashiwara [15] by simulating plastic strain and magnetic induction. Zero pop-in displacement in this region, which retains bulk grain size, means higher density of dislocations. The second section of punched cross section, sheared section (Fig. 14), was characterised by higher hardness near the edge compared to roll over and zero pop-in displacement. Fracture section (Fig. 15) showed hardness peak at a distance from the edge which was in good agreement with the microstructural observations from the band contrast maps (Fig. 5). Severe burr section (Fig. 16) showed zero pop-in displacement over the entire region due to plastic deformation. The size of the burr formed during punching depends on the clearance between the punch and the die during punching. An optimized clearance minimizes the deformation near the edge, improves the edge quality and therefore, plays an important role in designing the motor core laminations. Clearances generally range between $2 \%$ to $10 \%$ of the sheet thickness [11]. Most of the previous researchers have reported the deterioration of the magnetic properties during mechanical cutting, however, there is lack of information in the literature concerning the microstructural changes due to deformation and the associated magnetic deterioration. This paper gives a detailed microstructural and mechanical property characterization of a motor core lamination.

The summary of the mechanical properties of different microstructural features is given in Table 1. The total hardness change near the damaged edge can be attributed to the combined effect of grain refinement, work hardening and residual stress. The type of residual stress is also important to consider because tensile residual stress decreases hardness whereas compressive increases [33]. The amount of hardness increase due to work hardening also varies depending on the stress and strain level in that particular region. So, the process seems to be complex and therefore, we will discuss each section separately.

The roll over region is mainly characterized by stress induced grains with no change in grain size. The stress level is not high enough to form shear bands but the dislocation density increases which is confirmed by pop-in zero distance near the edge (Fig. 17). Therefore, the hardness increase is due to work hardening and residual stress as shown in Table 1. The sheared section also comprises of stress induced grains with no grain size change. The strain in this section is higher 
than roll over and dislocation density is increased. This is confirmed by pop-in zero displacement region extending up to $\sim 140 \mu \mathrm{m}$ from the edge (Fig. 17). The third region which is the fracture section having maximum heterogeneities have the total hardness increase by all the three factors (work hardening, grain refinement and residual stress). From the above discussion, it can be concluded that the hardness increase can be due to different factors and it is difficult to separate the compressive residual stress effect from the tensile residual stress because of the complexity of microstructure. 
Table 1 Mechanical properties in different sections of punched 35WW250 steel.

\begin{tabular}{|c|c|c|c|c|c|c|}
\hline Section & Microstructural features & $\begin{array}{l}\text { Av. } \\
\text { hardness } \\
\text { GPa }\end{array}$ & $\begin{array}{l}\text { Max. } \\
\text { Hardness } \\
\text { GPa }\end{array}$ & $\begin{array}{l}\text { Min. } \\
\text { Hardness } \\
\text { GPa }\end{array}$ & Std. Dev. & $\begin{array}{l}\text { Possible } \\
\text { reason } \\
\text { for } \\
\text { hardness } \\
\text { increase }\end{array}$ \\
\hline \multirow[t]{2}{*}{ Roll over } & $\begin{array}{l}\text { Region with no grain size } \\
\text { change but zero pop-in }\end{array}$ & 3.39 & 3.68 & 3.01 & 0.34 & $\begin{array}{l}\text { Work hardening }+ \text { Residual } \\
\text { stress }\end{array}$ \\
\hline & $\begin{array}{l}\text { Region with no grain size } \\
\text { change and non-zero pop-in }\end{array}$ & 3.3 & 3.46 & 3.08 & 0.19 & Residual stress \\
\hline Sheared & $\begin{array}{l}\text { Region with no change in grain } \\
\text { size but zero pop-in value }\end{array}$ & 3.43 & 3.6 & 3.1 & 0.17 & $\begin{array}{l}\text { Work hardening }+ \text { Residual } \\
\text { stress }\end{array}$ \\
\hline \multirow[t]{3}{*}{ Fracture } & $\begin{array}{l}\text { Ultrafine grains within the shear } \\
\text { bands }\end{array}$ & 3.98 & 4.54 & 3.48 & 0.38 & $\begin{array}{l}\text { Grain refinement +Work } \\
\text { hardening + Residual stress }\end{array}$ \\
\hline & $\begin{array}{l}\text { Region with no change in grain } \\
\text { size and non-zero pop-in value }\end{array}$ & 3.24 & 3.34 & 3.05 & 0.13 & Residual stress \\
\hline & Region where burr starts to form & 4.39 & 4.41 & 4.38 & 0.02 & $\begin{array}{l}\text { Grain refinement +Work } \\
\text { hardening + Residual stress }\end{array}$ \\
\hline \multirow[t]{2}{*}{ Burr } & Region with elongated grains & 3.61 & 4.01 & 3.49 & 0.31 & $\begin{array}{l}\text { Grain refinement +Work } \\
\text { hardening + Residual stress }\end{array}$ \\
\hline & $\begin{array}{l}\text { Region within undeformed } \\
\text { grain }\end{array}$ & 3.56 & 3.69 & 3.3 & 0.17 & $\begin{array}{l}\text { Work hardening }+ \text { Residual } \\
\text { stress }\end{array}$ \\
\hline
\end{tabular}

From all the above results and discussion derived from SEM and nanoindentation, the distance of damage near the punched edge was found out to be $\sim 300 \mu \mathrm{m}$. This damaged zone consists of severely plastic deformation regions and some undeformed grains with residual stress induced. 
The complex microstructural features of the damaged region near the punched edge can affect the magnetic properties of the electrical steel, such as core loss and permeability. The increase in the number of dislocations due to work hardening and shear band formation increases the pinning sites for magnetic domain movement [2]. This results in an increase in core loss and drop in permeability of the steel lamination. In addition, the formation of burr increases the extent of deformation during punching and therefore, maintaining an optimum clearance is very important for motor core manufacturing. Also, the residual stress induced by punching affects the magnetic properties of the electrical steel lamination where compressive residual stress increases losses and tensile decreases [15]. Therefore, the magnetic properties vary from one region to another near the punched edge of the lamination based on microstructure. This dependence of magnetic properties on microstructure requires an appropriate database to enable the adaption of an accurate model for punching effects during the design process.

\section{Conclusions}

The industrial punched sample was examined under electron microscope and the microstructural features which can deteriorate magnetic properties were analysed. The deformation structure formed due to punching was found to be heterogeneous and consisted of shear bands and ribbon grains. The ribbon grains were formed from stable crystal orientations, whereas shear bands were formed from unstable orientations. The increase in hardness for roll over section was small which was attributed to the plastic strain and tensile residual stress. Sheared section was characterised by plastic strain and residual stress. Ductile fracture section showed an increasing trend of hardness initially reaching a peak and then decreasing. Burr section was characterised by plastic strain which was indicated by zero pop-in displacement in the entire section. The dislocation density increased due to work hardening and shear band formation can be the major cause of deterioration of magnetic properties. This is because the dislocations act as hindrances to the motion of domains resulting in the increase of losses. Further, the distance of damage was maximum for the ductile fracture section among the other four sections, which means that magnetic property deterioration varies from one point to another within the damaged region. 


\section{Acknowledgements}

This work was supported by the Natural Sciences and Engineering Research Council of Canada, under their Collaborative Research and Development Grants Program. The authors would like to thank Infolytica and TM4 for providing the samples.

\section{References}

[1] Y. Kurosaki, H. Mogi, H. Fujii, T. Kubota, and M. Shiozaki, "Importance of punching and workability in non-oriented electrical steel sheets," J. Magn. Magn. Mater., vol. 320, no. 20, pp. 2474-2480, Oct. 2008.

[2] A. Pulnikov, P. Baudouin, and J. Melkebeek, "Induced stresses due to the mechanical cutting of non-oriented electrical steels," J. Magn. Magn. Mater., vol. 254-255, pp. 355357, Jan. 2003.

[3] C. Kaido, H. Mogi, M. Fujikura, and J. Yamasaki, "Punching Deterioration Mechanism of Magnetic Properties of Cores," IEEJ Trans. Fundam. Mater., vol. 128, no. 8, pp. 545-550, 2008.

[4] H. M. S. Harstick, M. Ritter, A. Plath, and W. Riehemann, "EBSD Investigations on Cutting Edges of Non-Oriented Electrical Steel," Metallogr. Microstruct. Anal., vol. 3, no. 4, pp. 244-251, Jul. 2014.

[5] A. Saleem, N. Alatawneh, R. R. Chromik, and D. A. Lowther, "Effect of Shear Cutting on Microstructure and Magnetic Properties of Non-Oriented Electrical Steel," IEEE Trans. Magn., vol. 52, no. 5, pp. 1-4, May 2016.

[6] F. J. G. Landgraf, “Nonoriented Electrical Steels,” JOM, vol. 64, no. 7, pp. 764-771, Jul. 2012.

[7] B. D. Cullity and C. D. Graham, Introduction to Magnetic Materials, 2nd edition. 2008.

[8] M. Emura, F. J. G. Landgraf, W. Ross, and J. R. Barreta, "The influence of cutting technique on the magnetic properties of electrical steels," J. Magn. Magn. Mater., vol. 254255, pp. 358-360, Jan. 2003.

[9] W. Shi, J. Liu, and C. Li, "Effect of cutting techniques on the structure and magnetic properties of a high-grade non-oriented electrical steel," J. Wuhan Univ. Technol.-Mater Sci Ed, vol. 29, no. 6, pp. 1246-1251, Dec. 2014.

[10] X. Xiong, S. Hu, K. Hu, and S. Zeng, "Texture and magnetic property evolution of nonoriented Fe-Si steel due to mechanical cutting," J. Magn. Magn. Mater., vol. 401, pp. 982990, Mar. 2016. 
[11] P. Baudouin, M. De Wulf, L. Kestens, and Y. Houbaert, "The effect of the guillotine clearance on the magnetic properties of electrical steels," J. Magn. Magn. Mater., vol. 256, no. $1-3$, pp. 32-40, Jan. 2003.

[12] Y. Kai, Y. Tsuchida, T. Todaka, and M. Enokizono, "Effect of local residual stress in rotating machine core on vector magnetic property," in 2010 XIX International Conference on Electrical Machines (ICEM), 2010, pp. 1-6.

[13] H. A. Weiss et al., "Influence of shear cutting parameters on the electromagnetic properties of non-oriented electrical steel sheets," J. Magn. Magn. Mater., vol. 421, pp. 250-259, Jan. 2017.

[14] K. Fujisaki et al., "Motor core iron loss analysis evaluating shrink fitting and stamping by finite-element method," IEEE Trans. Magn., vol. 43, no. 5, pp. 1950-1954, 2007.

[15] Y. Kashiwara, H. Fujimura, K. Okamura, K. Imanishi, and H. Yashiki, "Estimation model for magnetic properties of stamped electrical steel sheet," Electr. Eng. Jpn., vol. 183, no. 2, pp. 1-11, Apr. 2013.

[16] Y. Ding, M. Gallaugher, N. Brodusch, R. Gauvin, and R. R. Chromik, "Coating induced residual stress in nonoriented electrical steel laminations," J. Mater. Res., vol. 29, no. 16, pp. 1737-1746, 2014.

[17] “ASTM-E112 Standard Test Methods for Determining Average Grain Size.” 2013.

[18] W. C. Oliver and G. M. Pharr, "An improved technique for determining hardness and elastic modulus using load and displacement sensing indentation experiments," J. Mater. Res., vol. 7, no. 6, pp. 1564-1583, Jun. 1992.

[19] M. Göken and M. Kempf, "Pop-ins in Nanoindentations - the Initial Yield Point," Z. Fuer Met., vol. 92, no. 9, pp. 1061-1067, 2001.

[20] Z. Wang, "Influences of sample preparation on the indentation size effect and nanoindentation pop-in on nickel," Department of Materials Science \& Engineering, University of Tennessee, Knoxville, 2012.

[21] D. C. Joy, D. E. Newbury, and D. L. Davidson, "Electron channeling patterns in the scanning electron microscope," J. Appl. Phys., vol. 53, no. 8, pp. R81-R122, Aug. 1982.

[22] D. Dorner, S. Zaefferer, and D. Raabe, "Retention of the Goss orientation between microbands during cold rolling of an Fe3\%Si single crystal," Acta Mater., vol. 55, no. 7, pp. 2519-2530, Apr. 2007.

[23] B. Hutchinson, "Deformation microstructures and textures in steels," Philos. Trans. R. Soc. Lond. Math. Phys. Eng. Sci., vol. 357, no. 1756, pp. 1471-1485, Jun. 1999. 
[24] J. R. Bowen, P. B. Prangnell, and F. J. Humphreys, "Microstructural evolution during formation of ultrafine grain structures by severe deformation," Mater. Sci. Technol., vol. 16, no. 11-12, pp. 1246-1250, Nov. 2000.

[25] E. Frutos, M. Multigner, and J. L. González-Carrasco, "Novel approaches to determining residual stresses by ultramicroindentation techniques: Application to sandblasted austenitic stainless steel," Acta Mater., vol. 58, no. 12, pp. 4191-4198, Jul. 2010.

[26] T. Omura, Y. Zaizen, M. Fukumura, K. Senda, and H. Toda, "Effect of Hardness and Thickness of Nonoriented Electrical Steel Sheets on Iron Loss Deterioration by Shearing Process," IEEE Trans. Magn., vol. 51, no. 11, 2015.

[27] T. Ohmura, K. Tsuzaki, and F. Yin, "Nanoindentation-Induced Deformation Behavior in the Vicinity of Single Grain Boundary of Interstitial-Free Steel," Mater. Trans., vol. 46, no. 9, pp. 2026-2029, 2005.

[28] A. Barnoush, "Correlation between dislocation density and nanomechanical response during nanoindentation," Acta Mater., vol. 60, no. 3, pp. 1268-1277, Feb. 2012.

[29] A. Montagne, V. Audurier, and C. Tromas, "Influence of pre-existing dislocations on the pop-in phenomenon during nanoindentation in MgO," Acta Mater., vol. 61, no. 13, pp. 4778-4786, Aug. 2013.

[30] K. Matsumura and B. Fukuda, "Recent developments of non-oriented electrical steel sheets," IEEE Trans. Magn., vol. 20, no. 5, pp. 1533-1538, Sep. 1984.

[31] D. F. Bahr, D. E. Kramer, and W. W. Gerberich, "Non-linear deformation mechanisms during nanoindentation," Acta Mater., vol. 46, no. 10, pp. 3605-3617, Jun. 1998.

[32] T. Sakai, A. Belyakov, and H. Miura, "Ultrafine Grain Formation in Ferritic Stainless Steel during Severe Plastic Deformation," Metall. Mater. Trans. A, vol. 39, no. 9, p. 2206, May 2008 .

[33] S. Suresh and A. E. Giannakopoulos, "A new method for estimating residual stresses by instrumented sharp indentation," Acta Mater., vol. 46, no. 16, pp. 5755-5767, Oct. 1998. 